\title{
GLL
}

Geomatics, Landmanagement and Landscape No. $3 \cdot 2021,25-40$

\section{ANALYSIS OF HYPERBOLOID COOLING TOWER PROJECTION ON 2D SHAPE}

\author{
Andrzej Kwinta, Joanna Bac-Bronowicz
}

\begin{abstract}
Summary
This paper undertakes the problem of mapping a hyperboloid cooling tower on a single plane. Measurements performed by ground-based laser scanning technology quickly deliver substantial amounts of geometric data of the tower's outer wall. The essence of the article is projection of the rotational hyperboloid on a plane. The shape of the hyperboloid cooling tower is not directly expandable to a single plane. Mapping a hyperboloid shape on a plane is, therefore, associated with distortions. This paper presents a comparison between cylindrical and conic projection of a hyperboloid cooling tower. The most popular method of mapping hyperboloid is cylindrical projection. The cylinder's side surface is easily developed on the drawing sheet. For the hyperboloid cooling tower, the biggest distortions occur in the latitudinal direction and reach the highest values at the top and bottom edges. The equation (13) describe distortion for the cylindrical projection. The equation (18) describe distortion for the conical projection. This paper presents results obtained from the performed measurement. The analysis found that cone mapping produces less distortion than cylindrical projection for the hyperboloid cooling tower. We think, that in conical projection, the shape of a hyperboloid cooling tower and theoretical conic shape have better corresponding together than in cylindrical projection.
\end{abstract}

\section{Keywords}

hyperboloid cooling tower $\bullet$ tower measurement and analysis $\bullet$ cartographic projection $\bullet$ laser scanning

\section{Introduction}

Cooling towers are essential component of the industry infrastructure. They vary in size shape and type depending on the needs. Large facilities like power plants, oil refineries and steel manufacturing plants generally use hyperboloid cooling towers [Asadzadeh and Mehtab 2014, Lu et al. 2018]. Because of their distinctive shape and size, these objects easily attract attention. Unfortunately, these features also cause some inconveniences in measuring objects of this type [Feltens 2011].

As any engineering structure, a hyperboloid cooling tower is subjected to continuous load and undergoes deformation [Bamu and Zingoni 2005, Kulkarni and Kulkarni 
2014, Makuch 2018]. In addition, due to the tower's size, the deformation is affected by winds [Abu-Sitta and Hashish 1973, Baillis et al. 2000].

Information on the shape of the object, its dimensions and changes of the outer wall is provided by methods of non-contact surveying and photogrammetry [Chisholm 1977, Jasińska and Preweda 2004, Litwin and Piech 2013, Yang et al. 2016, Zhao 2018]. Especially the widespread introduction of terrestrial laser scanning allows one to quickly test a large number of points on objects which are difficult to access directly [Bajtala et al. 2011, Bala et al. 2012, Camp et al. 2013, Muszyński 2014, Gawronek and Mitka 2015, Kregar et al. 2015, Głowacki et al. 2016, Ioannidis et al. 2016, Pandžić 2016, Muszyński and Milczarek 2017, Makuch and Gawronek 2020].

$3 \mathrm{D}$ results of measurements of the hyperboloid cooling tower can be viewed in special software [Makuch 2018]. However, for example, where the results of measurements are intended to be used during repair works, it is necessary to present the outer wall of the cooling tower on a single plane (as a drawing). In this case, the image becomes distorted, because it is impossible to represent the hyperboloid directly on a plane and one needs to apply an appropriate projection [Snyder 1987]. This study compared the use of different cartographic projections to map the surface of the hyperboloid cooling tower on a single plane.

\section{Hyperboloid}

The equation for the hyperboloid cooling tower outer wall surface can be found in the literature [Gould and Kratzig 1998]. Let us consider the general equation of the single hyperboloid:

$$
\frac{x^{2}}{a^{2}}+\frac{y^{2}}{b^{2}}-\frac{z^{2}}{c^{2}}=1
$$

We shall accept a number of assumptions that simplify and define the object of the analysis and take into account additional markings as shown in Figure 1. We shall have:

- the object of analysis is a rotational single-sheet hyperboloid,

- the height of the object is $z=H$,

- the radius of the base $R_{0}$,

- the radius at the upper edge $R_{H}$,

Based on the above Figure 1, assumptions and dependencies (1), hyperboloid equation (radius) can be written as:

$$
R_{c}(z)=R_{H} \sqrt{1+\frac{(H-z)^{2}}{c^{2}}}
$$

where: $c^{2}=\frac{H^{2} R_{H}^{2}}{R_{0}^{2}-R_{H}^{2}}$ 
or:

$$
R_{c}(z)=\sqrt{R_{H}^{2}+\left(1-\frac{z}{H}\right)^{2}\left(R_{0}^{2}-R_{H}^{2}\right)}
$$

The equation of hyperboloid points in a rectangular pattern:

$$
\begin{aligned}
& x=R_{c}(z) \cos (\varphi) \\
& y=R_{c}(z) \sin (\varphi) \\
& z=H-c \sqrt{\frac{R_{c}^{2}(z)}{R_{H}^{2}}-1}
\end{aligned}
$$

where:

$360 \operatorname{deg} \geq \varphi \geq 0 \operatorname{deg}$

$R_{0} \geq R_{c}(z) \geq R_{H}$

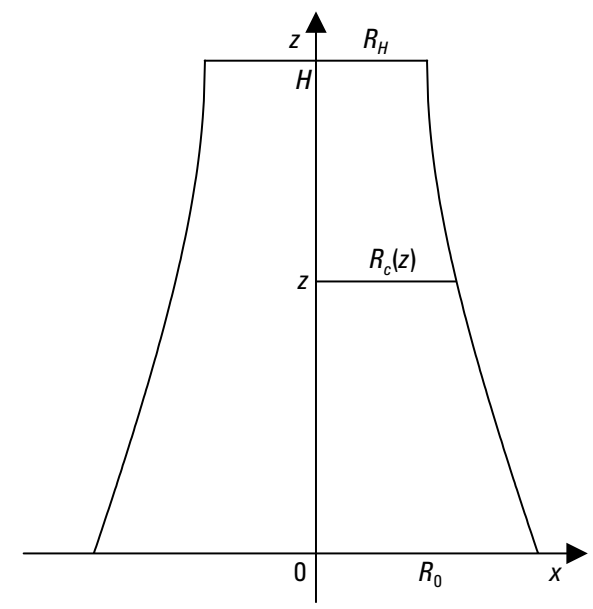

Source: Authors'study

Fig. 1. Calculation scheme of hyperboloid (section through a hyperboloid)

The above equations show that the hyperboloid can be described by three parameters $H, R_{H}, R_{0}$. These parameters can be determined by least squares from measurements of the cooling tower's wall. Based on measurements of the structure (cooling tower), we obtain a set of points in space that describes the object. Laser scanning facilitates measurements of cooling towers, because it allows one to measure a large number of points in a brief period of time [Ioannidis et al. 2006, Camp 2013].

In order to determine the parameters of the hyperboloid, we need first to transform coordinates to a local coordinate system in which the axis $\mathrm{z}$ coincides with the axis of the hyperboloid, and zero is assigned to its lowest point. The coordinates of a point and its distance from the axis can be written down as follows: 


$$
\begin{aligned}
& x_{i}=X_{i}-\frac{\sum_{i=1}^{n} X_{i}}{n} \\
& y_{i}=Y_{i}-\frac{\sum_{i=1}^{n} Y_{i}}{n} \\
& z_{i}=Z_{i}-\min \left(Z_{i}\right) \\
& R_{i}=\sqrt{x_{i}^{2}+y_{i}^{2}}
\end{aligned}
$$

where:

$X_{i}, Y_{i}, Z_{i}-$ coordinates of the $i$-th measurement point,

$n$ - quantity of measurement points,

$R_{i} \quad$ - distance of the point i from the axis of the cooling tower.

According to the method of least squares, parameters of the hyperboloid are determined in such a manner that the sum of the squares of distances between the hyperboloid and the set of measurement points is minimal. For every point, we can record the linearized observation equation in the following form:

$$
R_{i}+v_{i}=R_{c}\left(H^{0}, R_{H}^{0}, R_{0}^{0}, z_{i}\right)+\frac{\partial R_{c}}{\partial H} d H+\frac{\partial R_{c}}{\partial R_{H}} d R_{H}+\frac{\partial R_{c}}{\partial R_{0}} d R_{0}
$$

where:

$v_{i} \quad$ - deviation for a single point (distance of the measuring point from the hyperboloid),

$R_{c}\left(H^{0}, R_{H}^{0}, R_{0}^{0}, z_{i}\right)$ - the approximate value of the radius of the hyperboloid.

In this way, a system of $n$ equations with three unknowns is created, from which one can determine another system of normal equations. With such a system of normal equations, one can determine growth parameters of proxies. Since the calculations shall use approximate values of the parameters, they must be performed by iteration. Finally, hyperboloid parameters are calculated as follows:

$$
\begin{aligned}
& H=H^{0}+d H \\
& R_{H}=R_{H}^{0}+d R_{H} \\
& R_{0}=R_{0}^{0}+d R_{0}
\end{aligned}
$$

As a result of the calculations, one can also determine the average error of hyperboloid to results rate, as well as errors in the set parameters. 
On the hyperboloid surface, we can overlay the coordinate grid in the form of parallels and meridians. The parallels are marked by intersections of the hyperboloid with horizontal planes, while the meridians are marked by intersections of the hyperboloid with vertical planes passing through the axis of the hyperboloid (Fig. 2).

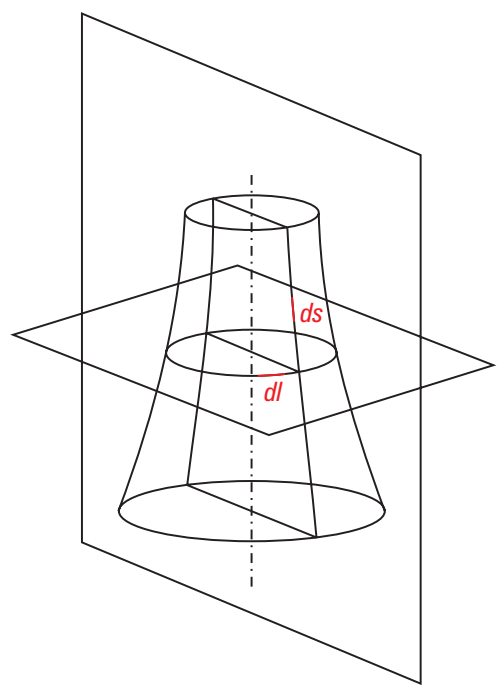

Source: Authors' study

Fig. 2. Traces of intersections hyperboloid by a vertical and horizontal plane

Because hyperboloid is the surface of the second-degree non-evolving on the plane, so to present it on the plane should be carried out projection on the plane or evolved surface. In our case analysis we give projection on two surfaces, which are evolve able, i.e., on the side surface cylinder and cone.

The map projection [Snyder 1987] is a mathematically determined method of presenting the entire globe or a part thereof on a plane. More generally speaking, mapping is a mathematically described projection of any object on a drawing sheet. Over the centuries, humanity developed many cartographic representations to depict the Earth on a sheet [Grafarend and Krumm 2006]. With the development of astronomical measurements there arose a need for imaging objects with irregular shapes [Nyrtsov 2003, Berthoud 2005]. In many cases, the shape of an object is not expandable to a plane, which causes mapping distortions. Linear mapping distortions are associated with a linear scale of the map. Linear scale mapping is the ratio of the distance of a projection to the length of the segment mapped.

We shall examine the linear distortions in the main directions. If we mark the length of a section along the meridian (on vertical plane) as s and the length of one running along the parallel as 1, we can formulate the following relationships [Snyder 1987]: 


$$
\begin{aligned}
& m=\frac{d s^{\prime}}{d s} \\
& n=\frac{d l^{\prime}}{d l}
\end{aligned}
$$

while the distortion coefficients in the mapping can be described as follows:

$$
\begin{aligned}
& M=m-1=\frac{d s^{\prime}}{d s}-1 \\
& N=n-1=\frac{d l^{\prime}}{d l}-1 \\
& P=\sqrt{M^{2}+N^{2}}
\end{aligned}
$$

where:

$d s, d l$ - slight increases in length of sections of the hyperboloid,

$d s^{\prime}, d l^{\prime}$ - slight increases in length of sections on the map.

As shown in Figure 2 and Formula (3), the increase of length of the parallels can be described as:

$$
d l=R(z) d \varphi
$$

and the slight increase in the length of the meridian can be written down as follows:

$$
d s^{2}=d R^{2}+d z^{2}
$$

which, on the basis of (3), leads to the relation:

$$
d s=\sqrt{\frac{(H-z)^{2} b^{2}+c^{2}}{(H-z)^{2}+c^{2}}} d z
$$

where: $b^{2}=\frac{\left(R_{0}^{2}-R_{H}^{2}\right)+H^{2}}{H^{2}}$

To calculate the length of the meridian arc, one should integrate relationship (11), leading to an elliptic integral of the second kind [Byrd 1954].

The above relationship can be used to determine the projection parameters and to define the distortions emerging in these projections.

\section{Cylindrical projection}

In this projection, the surface on which it is overlaid is the side surface of a cylinder [Snyder 1987]. The cylinder's side surface is then easily developed on the drawing sheet. The cylinder equation should be adjusted so that the cylinder axis coincides with the axis of the object, and the radius, which is constant, should determine the average point 
distance of the cooling tower walls from the axis. In Figure 3, the calculation diagram is depicted.

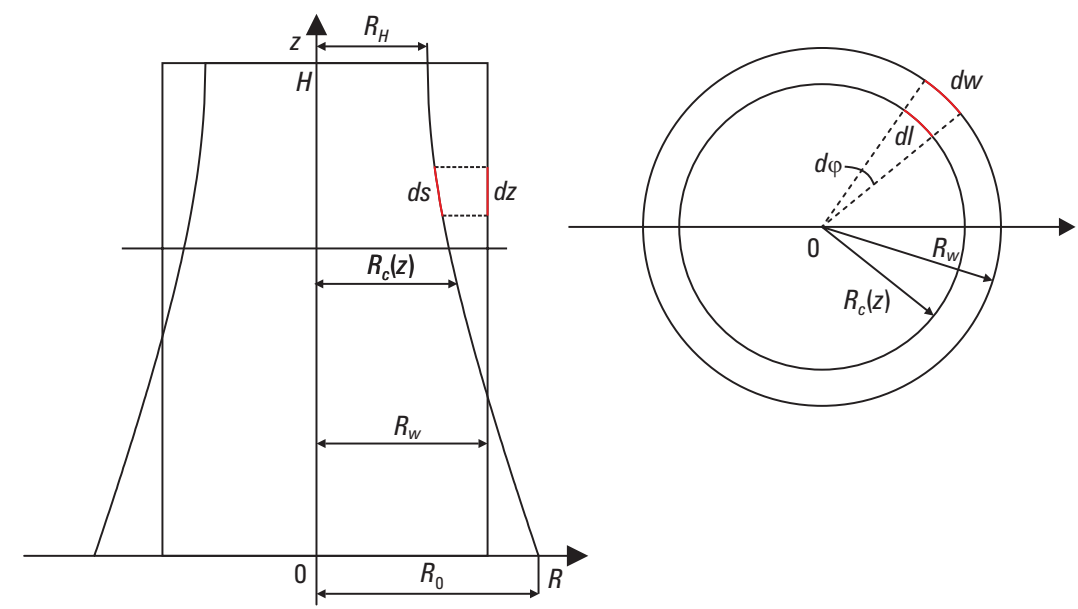

Source: Authors' study

Fig. 3. Calculation diagram of hyperboloid in cylindrical projection

According to Figure 3, the equation of the cylinder surface can be described as follows:

$$
\begin{aligned}
& x=R_{w} \cos (\varphi) \\
& y=R_{w} \sin (\varphi) \\
& z=z
\end{aligned}
$$

where:

$360 \mathrm{deg} \geq \varphi \geq 0 \mathrm{deg}$

$H \geq z \geq 0$

In Figure 3, images of latitudes and longitudes in a cylindrical projection are indicated. According to the accepted signatures and using the formulas (2), (9) and (11), the equation (8) for the cylindrical projection can be written as follows:

$$
\begin{aligned}
& M_{w}=\sqrt{\frac{(H-z)^{2}+c^{2}}{(H-z)^{2} b^{2}+c^{2}}-1} \\
& N_{w}=\frac{R_{w}}{R_{c}(z)}-1=\frac{c R_{w}}{R_{H} \sqrt{(H-z)^{2}+c^{2}}}-1
\end{aligned}
$$


As can be seen from the relation (13), the distortion depends on the altitude meridian coordinate $z$, while the latitudinal distortion depends also on the radius of the cylinder which we are mapping. The maximum value of the distortion can be determined from (8). Let us adopt the cylinder radius value based on the measurements as the arithmetic mean of the distance from the cooling tower shell axis. Based on (4) and (12) we have:

$$
R_{w}=\frac{\sum_{i=1}^{n} R_{c}\left(z_{i}\right)}{n}
$$

Figure 4 below shows the distribution of coefficients of the distortion function $z$. Red color indicates the distribution of distortions for the cylindrical projection.

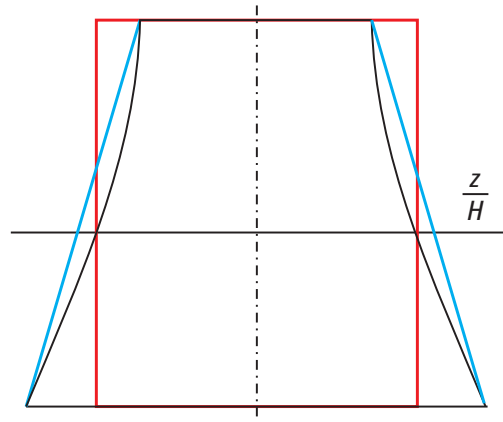

Source: Authors' study

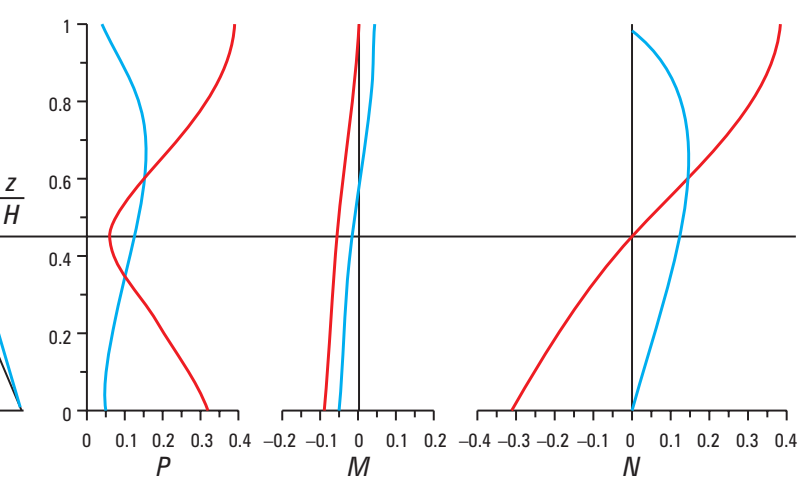

$\overline{\text { Fig. 4. The distribution plots of distortion in the direction of the axis } \mathrm{z} \text { in cylindrical and conical }}$ projection

As you can see from the above figure, the biggest distortions occur in the latitudinal direction and reach the highest values at the top and bottom edges of the hyperboloid.

\section{Conical projection}

In this projection, the surface on which the projection is overlaid, is the side surface of a cylinder [Snyder 1987]. The side surface of the cone is developable on the drawing sheet. The equation of the cone must be chosen so that its axis coincides with the axis of the hyperboloid, and with a radius which is a linear function of the height that will meet the assumption of minimizing the sum of squares of the distances from the axis of the cooling tower outer walls. Figure 5 shows a diagram of the calculations. 


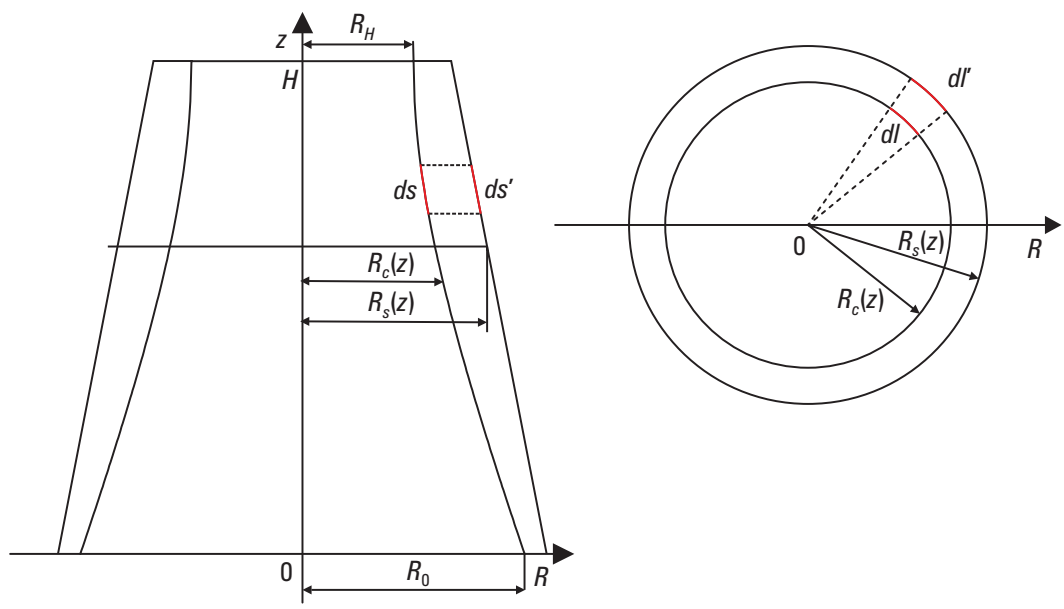

Source: Authors' study

Fig. 5. Calculation diagram of hyperboloid in conical projection

As shown in Figure 5, the cone equation can be described as follows:

where:

$$
\begin{aligned}
& x=R_{s}(z) \cos (\varphi) \\
& y=R_{s}(z) \sin (\varphi) \\
& z=\frac{R_{s}(z)-p}{k}
\end{aligned}
$$

$360 \operatorname{deg} \geq \varphi \geq 0 \operatorname{deg}$

$\mathrm{H} \geq z \geq 0$

$p, k$ - parameters of conic.

Let us assume the form of a cone (cone shape parameters) on the basis of measurements in accordance with the method of least squares. In this case, we will have to deal with linear regression, so parameters can be calculated according to:

$$
\begin{gathered}
k=\frac{n \sum_{i=1}^{n} R_{i} z_{i}-\sum_{i=1}^{n} R_{i} \sum_{i=1}^{n} z_{i}}{n \sum_{i=1}^{n} z_{i}^{2}-\left(\sum_{i=1}^{n} z_{i}\right)^{2}} \\
p=\frac{\sum_{i=1}^{n} R_{i} \sum_{i=1}^{n} z_{i}^{2}-\sum_{i=1}^{n} R_{i} z_{i} \sum_{i=1}^{n} z_{i}}{n \sum_{i=1}^{n} z_{i}^{2}-\left(\sum_{i=1}^{n} z_{i}\right)^{2}}
\end{gathered}
$$


Figure 5 contains images of latitude and longitude in the conical projection. We can determine the formulas for the mapping distortions in the main directions. Relevant images of latitudes and longitudes of the conical projection take the form of:

$$
\begin{aligned}
& d s^{\prime}=\sqrt{1+k^{2}} d z \\
& d l^{\prime}=R_{s}(z) d \varphi
\end{aligned}
$$

which leads to the following formulas for mapping distortions:

$$
\begin{aligned}
& M_{s}=\sqrt{\frac{\left[(H-z)^{2}+c^{2}\right]\left(1+k^{2}\right)}{(H-z)^{2} b^{2}+c^{2}}-1} \\
& N_{s}=\frac{R_{s}}{R_{c}(z)}-1=\frac{c[k z+p]}{R_{H} \sqrt{(H-z)^{2}+c^{2}}}-1
\end{aligned}
$$

The results of the calculation of distortion in the conical projection are shown in blue in Figure 4.

\section{Example}

The distributions of mapping distortions of the imaging of the hyperboloid cooling tower were analyzed on the basis of measurements of the real object. A detailed description of the object performed measurements and their processing into a point cloud are presented in M. Makuch's doctoral dissertation [Makuch 2018] and publication [Makuch and Gawronek 2020].

The measurement of the cooling tower was performed with the use of the Riegl VZ-400 laser scanner. The data were obtained from four positions around the facility [Makuch 2018]. As the points binding the scans obtained from the individual positions, reference objects were used, in the form of clearly identifiable points from a point cloud of rotational and tippable discs with a diameter of 6". The data, obtained by groundbased laser scanner were pre-treated in the Cyclone software. Found in their own systems of point clouds, they were located and oriented relative to a single coordinate system. Measurements were carried out with an average error RMS $=0.002 \mathrm{~m}$. Then, the cloud of points was manually cleared of erroneous and redundant observations and unified, limiting the amount of data obtained to a set of 35176 points (Fig. 6). Then, the data relevant to the geometry of the cooling tower walls were processed in two projections. All calculations were performed in specially prepared software "CTP1" (Colier Tower Projection), and contours were generated using Surfer software.

The measurements and the study adopted a local coordinate system, where the $\mathrm{x}$-axis was directed east. In accordance with the formulas given in section 2, the determination of hyperboloid parameters was performed, yielding the following results: 


$$
\left\{\begin{array}{l}
R_{H}=12.825 \mathrm{~m} \\
R_{0}=21.597 \mathrm{~m} \\
H=51.444 \mathrm{~m}
\end{array}\right.
$$

the average fit error of the theoretic rotational hyperboloid in relation to the measuring points was $\pm 0.184 \mathrm{~m}$.

Based on the dependence from section 3, the cylinder radius was determined by the least squares method which amounted to:

$$
R_{w}=16.150 \mathrm{~m}
$$

meanwhile, based on the formulas (16), the cone equation was determined:

$$
R(z)_{s}=-0.146 z+20.174
$$

The results of the calculations are graphically presented in Figures 7 and 8.
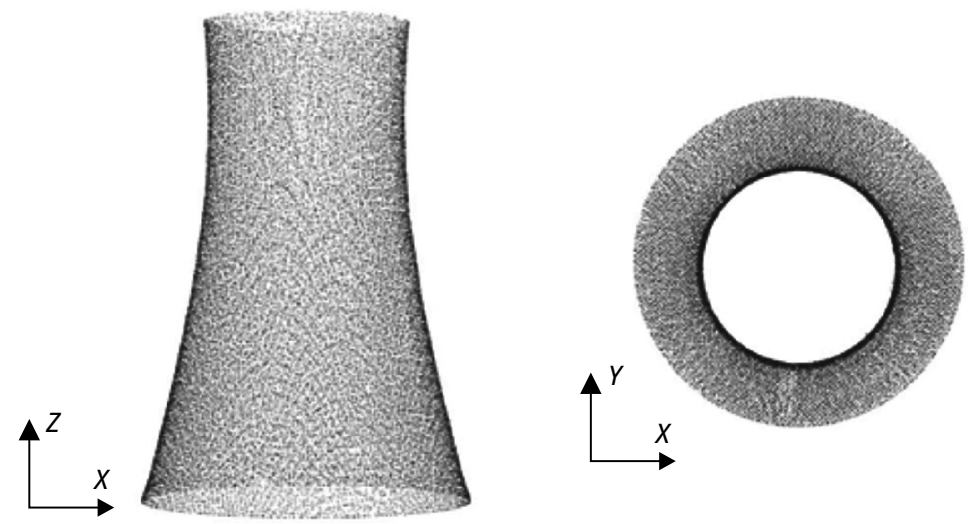

Source: Authors' study

Fig. 6. Measurement points cloud

The upper graphs show the distributions of maximum mapping distortions obtained from the equations (8), (13) and (18). On the lower graphs, you can see the distributions of distortion between the cooling tower walls and the designated rotational hyperboloid in the corresponding projections. Contours in Figures 7 and 8 are not smooth lines, due to a dense sampling of the cooling tower and the dimensioning of the grid used in the interpolation of contours. The issue of selecting an appropriate measuring grid and interpolation grid is a critical issue in the processing and visualization of measurement data [Bac-Bronowicz 2005].

Analyzing the results which are presented graphically in Figures 7 and 8 it must be held that much less mapping distortion emerge for the cone projection than for 

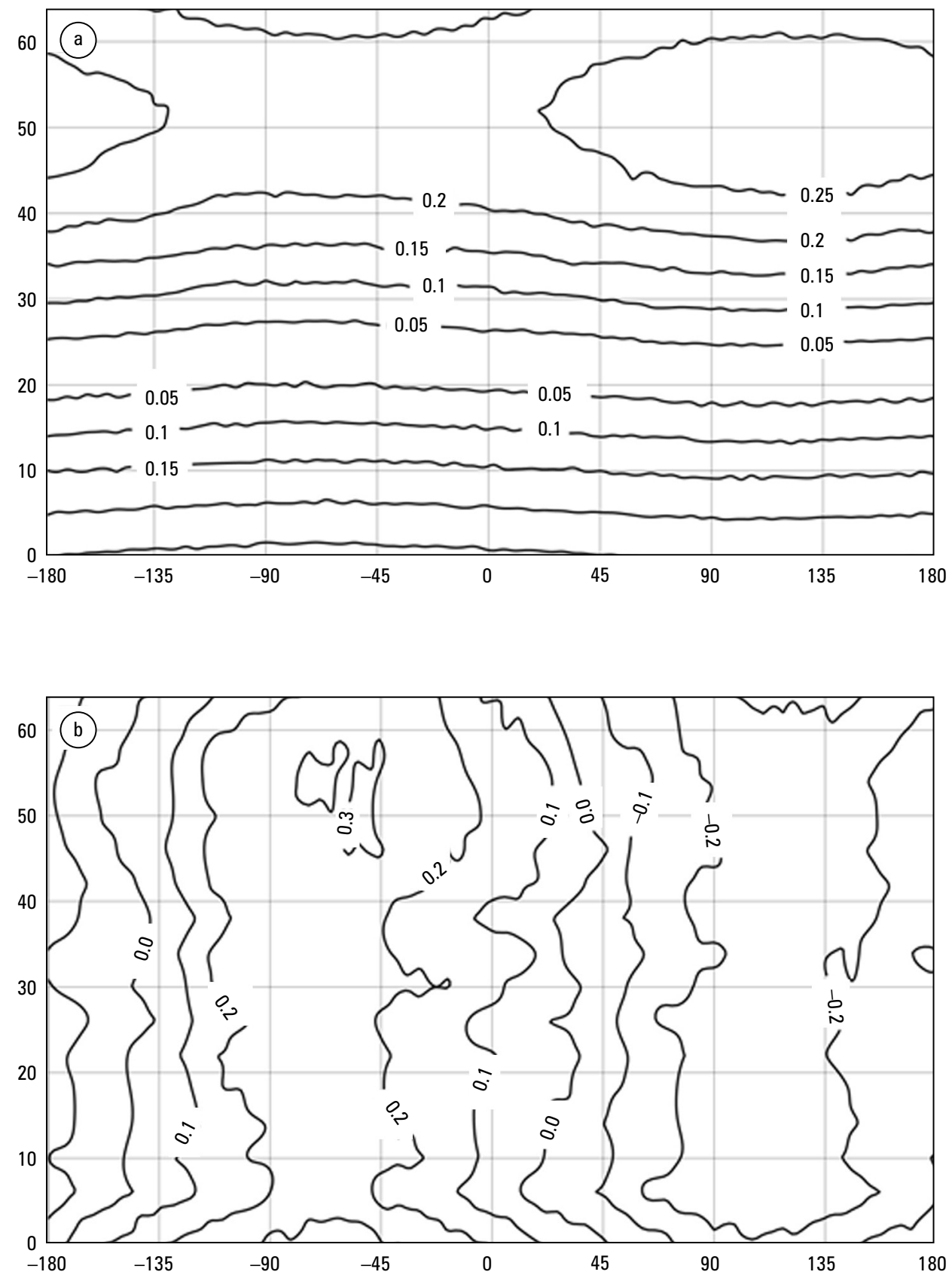

Source: Authors' study

Fig. 7. Results of calculation for cylindrical projection: a) maximum mapping distortions (8) and (13), b) distortion between the cooling tower walls and the designated rotational hyperboloid 

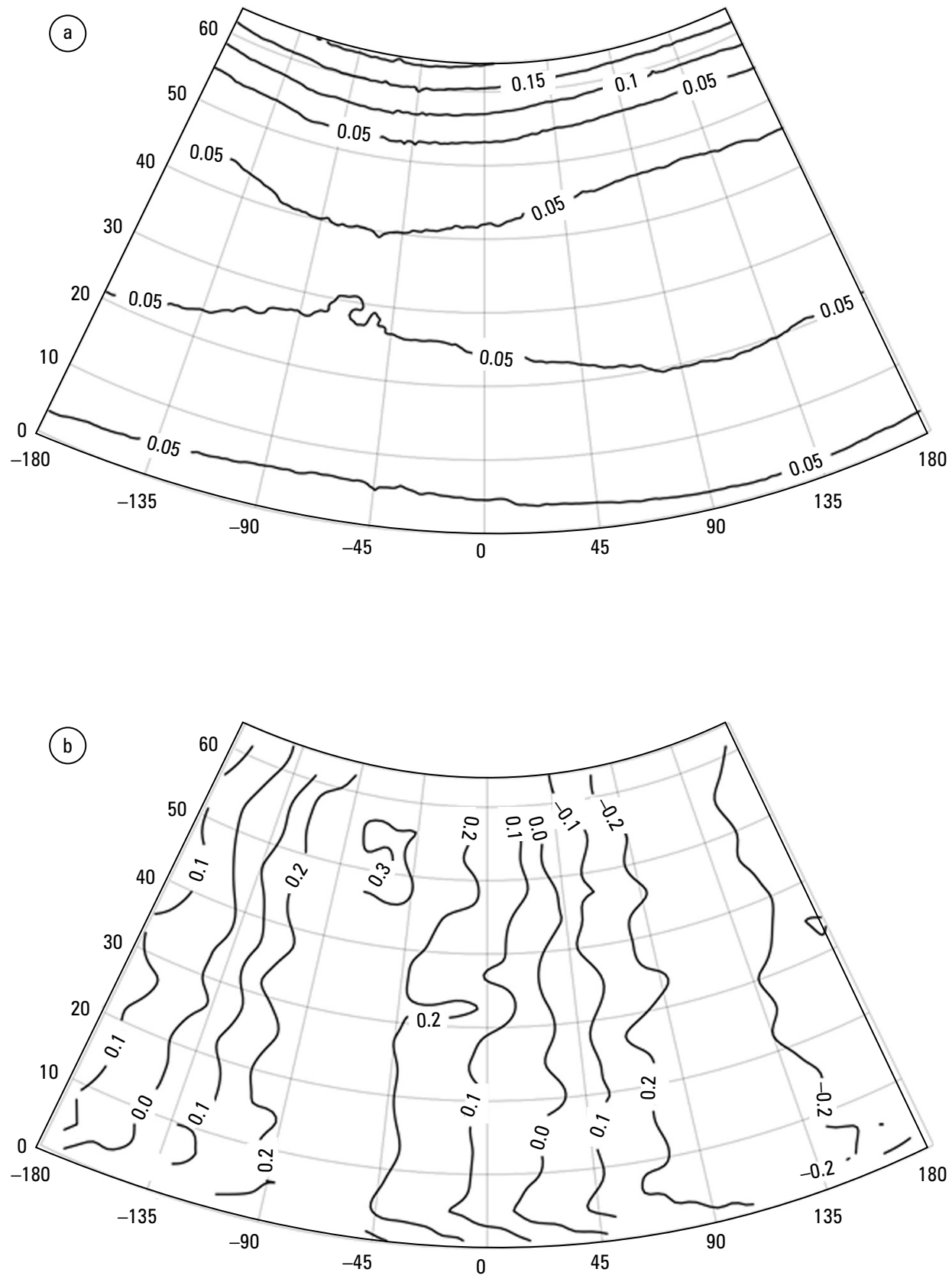

Source: Authors'study

Fig. 8. Results of calculation for conical projection: a) maximum mapping distortions (8) and (18), b) distortion between the cooling tower walls and the designated rotational hyperboloid 
the cylindrical projection. In the cylindrical projection (Fig. 7) and cone projection (Fig. 8) the largest mapping distortions occur in the upper part of the cooling tower. Distribution of baseline deviations coat cold of hyperboloid is co-shaped in both projections. The greatest deformations of the shape of the cooling tower walls emerge in the north and north-east direction, as well as south and south-west. Given the mapping distortions shown in the upper graphs, the obtained conical projection is a better representation of the real image.

\section{Summary}

The specificity of hyperboloid cooling towers contributes to the fact that these objects should be particularly carefully supervised. In Polish conditions, the maintenance checks are of particular importance, since the majority of cooling towers exceeded their design lifetimes, after which threats to their security significantly increase. Properly executed diagnostics of the condition of the outer walls should clearly show any deformation, loss, damage, and other anomalies on their surface. The article presented the problem of mapping a hyperboloid cooling tower on a plane, allowing a clear, twodimensional representation of the state of the surface structure. The shape of the hyperboloid cooling tower is not directly expandable on a plane and its mapping involves the introduction of distortions. The presented comparison of cylindrical and tapered mapping of the hyperboloid cooling tower showed that the cone mapping produces less distortion than a cylindrical projection. Carried out based on a real-life object, measured by a terrestrial laser scanner method, the study has demonstrated that imaging of a cooling tower outer walls on a plane using a conical projection result in a more readable and truer imaging representation of the object's surface.

\section{References}

Abu-Sitta S.H., Hashish M.G. 1973. Dynamic Wind Stresses in Hyperbolic Cooling Towers. Journal of the Structural Division, 99, 9, September, 1823-1835.

Asadzadeh E., Mehtab A. 2014. A Survey on Hyperbolic Cooling Towers. International Journal of Civil, Architectural, Structural and Construction Engineering, 8, 1022-1034.

Bac-Bronowicz J. 2005. Topographic factors as a usable tool for right modelling of continuous features measured in point. Mat. XXII ICC, ICA, A Coruna.

Baillis Ch., Julian J.F., Limam A. 2000. An enriched 2D modelling of cooling towers. Effects of real damage on the stability under self-weight and on the strength under wind pressure. Engineering Structures, 22, Elsevier, 831-846.

Bajtala M., Brunčák P., Kubinec J., Lipták M., Sokol Š. 2011. Exploitation of Terrestrial Laser Scanning in Determining of Geometry of a Factory Chimney. Proceedings of the 5th International Conference on Engineering Surveying (INGEO 2011). Brijuni, Croatia, September 22-24, 77-82.

Bala A.C., Brebu F.M., Moscovici A.M. 2012. Using terrestrial laser scanning technologies for high construction monitoring. 12th International Multidisciplinary Scientific GeoConference. Conference Proceedings, 2, 17-23 June, 829-836. 
Bamu P.C., Zingoni A. 2005. Damage, deterioration and the long-term structural performance of cooling-tower shells: A survey of developments over the past 50 years. Engineering Structures, 27, 12, Elsevier, 1794-1800.

Berthoud M.G. 2005. An equal-area map projection for irregular objects. Icarus, 175. Elsevier, 382-389.

Byrd P.F., Friedman M.D. 1954. Handbook of elliptic integrals for engineers and physicists. Springer-Verlag.

Camp G., Carreaud P., Lançon H. 2013. Large structures: which solutions for health monitoring? International Archives of the Photogrammetry, Remote Sensing and Spatial Information Sciences, XL-5/W2. XXIV International CIPA Symposium, 2-6 September, 137-141.

Chisholm N.W.T. 1977. Photogrammetry for cooling tower shape surveys. The Photogrammetric Record, IX (50), October, 173-191.

Feltens J. 2011. Hyperboloidal coordinates: transformations and applications in special constructions. Journal of Geodesy, 85, 4, 239-254.

Gawronek P., Mitka B. 2015. The use of terrestrial laser scanning in monitoring of the residential barracks at the site of the former concentration camp Auschwitz II - Birkenau. Geomatics, Landmanagement and Landscape, 3, 53-60.

Głowacki T., Grzempowski P., Sudoł E., Wajs J., Zając M. 2016. The assessment of the application of terrestrial laser scanning for measuring the geometrics of cooling towers. Geomatics, Landmanagement and Landscape, 4, 49-57.

Gould P.L., Kratzig W.B. 1998. Cooling Tower Structures. In: Handbook of Structural Engineering. Chen W. (ed.). CRC Press LLC, chapter 14, 473-504.

Grafarend E.W., Krumm F.W. 2006. Map projection: Cartographic Information Systems. Springer-Verlag, Berlin.

Ioannidis C., Valani A., Georgopoulos A., Tsiligiris E. 2006. 3D model generation for deformation analysis using laser scanning data of a cooling tower. 3rd IAG/12th FIG Symposium, Baden, May 22-24.

Jasińska E., Preweda E. 2004. A Few Comments on Determining the Shapes of Hyperboloid Cooling Towers by the Means of Ambient Tangents Method. Geodezja, 10, 1. AGH, Krakow.

Kregar K., Ambrožič T., Kogoj D., Vezočnik R., Marjetič A. 2015. Determining the inclination of tall chimneys using the TPS and TLS approach. Measurement, 75, 354-363.

Kulkarni S., Kulkarni A.V. 2014. Static and dynamic analysis of hyperbolic cooling tower. Journal of Civil Engineering Technology and Research, 2, 1, 39-61.

Litwin U., Piech I. 2013. Application of the photogrammetric method in surveying of the palace and park complex building in Mściwojów, Poland. Geomatics, Landmanagement and Landscape, 2, 37-44.

Lu Y., Klimenko A., Russell H., Dai Y., Warner J., Hooman K. 2018. A conceptual study on air jet-induced swirling plume for performance improvement of natural draft cooling towers. Applied Energy, 217, 496-508.

Makuch M. 2018. Application of terrestrial laser scanning in the process of modernization of hyperboloid cooling towers. Faculty of Environmental Engineering and Land Surveying, University of Agriculture in Krakow, phD thessis. Krakow (in Polish).

Makuch M., Gawronek P. 2020. 3D Point Cloud Analysis for Damage Detection on Hyperboloid Cooling Tower Shells. Remote Sensing, 12(10), 1542.

Muszyński Z. 2014. Application of robust estimation methods to calculation of geometric distortions of a cooling tower shell. In: 14th International Multidisciplinary Scientific GeoConference SGEM 2014: GeoConference on informatics, geoinformatics and remote sensing: 
Conference proceedings. Albena, Bulgaria, 17-26 June, 2, Geodesy and mine surveying: STEF92 Technology, 65-72.

Muszyński Z., Milczarek W. 2017. Application of Terrestrial Laser Scanning to Study the Geometry of Slender Objects. IOP Conference Series: Earth and Environmental Science, 95, 1-7.

Nyrtsov M.V. 2003. The classification of projections of irregularly shaped celestial bodies. Proceedings of the 21st International Cartographic Conference (ICC), Durban.

Pandžić J., Pejić M., Božić B., Erić V. 2016. TLS in Determining Geometry of a Tall Structure, Engineering Geodesy for Construction Works, Industry and Research. Proceedings of the International Symposium on Engineering Geodesy. Varaždin, Croatia, 20-22 May, 279-290.

Snyder J.P. 1987. Map Projections. A Working Manual. U.S. Geological Survey Professional Paper 1395. United States Government Printing Office, Washington.

Zhao X., Kargoll B., Omidalizarandi M., Xu X., Al Khatib H. 2018. Model Selection for Parametric Surfaces Approximating 3D Point Clouds for Deformation Analysis. Remote Sensing, 10(4), 634. https://doi.org/10.3390/rs10040634

Dr hab. inż. Andrzej Kwinta, prof. UR

University of Agriculture in Krakow

Department of Geodesy

30-149 Kraków, ul. Balicka 253a

Correspondence address:

al. Mickiewicza 21, 30-120 Kraków

e-mail: andrzej.kwinta@urk.edu.pl

ORCID: 0000-0002-2003-7703

Prof. dr hab. inż. Joanna Bac-Bronowicz

Wrocław University of Science and Technology

Department of Geotechnology, Hydro Technology,

and Underground and Hydro Engineering

Wybrzeże Wyspiańskiego 27, 50-370 Wrocław

e-mail: joanna.bac-bronowicz@pwr.edu.pl

ORCID: 0000-0001-9038-1131 